\title{
Evaluation of seismic performance measures for MDOF RC structures subjected to simulated and real ground motions
}

\author{
Shaghayegh Karimzadeh ${ }^{1, *}$, Aysegul Askan ${ }^{1}$ and Ahmet Yakut $^{1}$ \\ ${ }^{1}$ Civil Engineering Department, Middle East Technical University, Ankara, Turkey
}

\begin{abstract}
Nonlinear time history analyses of structures require full time series of ground motion records. For regions with sparse seismic networks or potential large earthquakes, ground motion simulation has gained more attention in recent years. Simulated records are required to be generated using regional input dataset and then verified against existing recorded ground motions of past events. To use simulated ground motions in engineering applications, estimation of reliable seismic demand parameters is essential. In this study, the real and simulated records of the 2009 L'Aquila, Italy earthquake with $(\mathrm{Mw}=6.3)$ are investigated for their use in engineering practice. In the first step, misfits are evaluated for alternative seismological measures (peak values, duration and frequency as well as energy content of the time histories). Next, varying multi-degree-offreedom reinforced concrete structures with different number of stories are selected. Numerical models of the structures are performed in the OpenSees platform. Seismic performance measures in terms of inter-story drift ratio for the selected structures are assessed through nonlinear time history analyses for both the real and simulated ground motions. Then, the misfits are estimated in terms of structural demand parameters. Results reveal a good fit between the seismological and engineering demand misfits for the selected ground motion simulation approaches.
\end{abstract}

\section{Introduction}

Seismic behavior of different types of structures is generally affected by alternative characteristics of ground motion records including amplitudes, durations, energy, and their frequency content. For accurate seismic structural response evaluation of structures, the use of Nonlinear Time History Analysis (NLTHA) is recommended by most of the seismic design codes (e.g.: [1-2]). NLTHA requires full time series of ground motion records. In regions with sparse ground motion data or large earthquakes with long return periods, an alternative to real ground motion records is the use of regionally simulated ground motions. There are three main ground motion simulation techniques: deterministic, stochastic, and hybrid methods (e.g.: [3-8]). Alternative ground motion simulation methods involve different computing costs and provide different levels of accuracy. Thus, several

\footnotetext{
* Corresponding author: ayakut@ metu.edu.tr
} 
seismological measures are introduced to evaluate the Goodness-Of-Fit (GOF) between the recorded and simulated ground motion time histories (e.g.: [9-10]).

Although it is important to evaluate the GOF between the observed and simulated seismological parameters, a major research field that remains open is concerned with their use in earthquake engineering. Simulations have recently been of particular interest in earthquake engineering as they can practically reflect the physics of earthquakes, the faulting mechanisms and the regional seismic parameters (e.g.: [11-15]). Recent studies reveal that the characteristics of input ground motions can affect engineering demand parameters. Therefore, before their use in earthquake engineering, it seems necessary to examine the closeness of the seismological misfits to the ones obtained based on engineering demand parameters for the simulated and real ground motion datasets. To accomplish this, as an initial trial in this study, the real and simulated records of the 2009 L'Aquila, Italy earthquake with a moment magnitude of 6.3 are evaluated through the definition of logarithmic misfit. For this purpose, the simulated records of two alternative simulation approaches (i.e.: Stochastic and Hybrid) are considered [13]. In the first part of this study, the seismological logarithmic misfits are evaluated for certain seismological measures including peak values, duration, and frequency as well as the energy content of the time histories. In the next step, a total of nine Multi-Degree-Of-Freedom (MDOF) Reinforced-Concrete (RC) frames with different number of stories are selected and then structural responses in terms of maximum inter-story drift ratios corresponding to the real and simulated ground motion datasets are calculated. Finally, structural logarithmic misfits are calculated in terms of the selected structural parameter (maximum inter-story drift ratio).

\section{Input ground motion records}

In this study, the observed and simulated time histories from two alternative approaches corresponding to the 2009 L'Aquila earthquake with $\mathrm{Mw}=6.3$ are employed. The earthquake occurred in central Italy in the close vicinity of the town L'Aquila on a normal fault. For misfit evaluation, a total of seven stations mostly located on rock sites [10] are selected. Table 1 presents information including the site classes, Latitude, Longitude, station code, epicentral distance ( $\mathrm{R}_{\mathrm{EPI}}$ ), and observed Peak Ground Accelerations (PGAs) in both North-South (NS) and East-West (EW) directions.

In this study, the validated simulated records from two alternative ground motion simulation techniques by previous studies are employed [13, 16-17]. The investigated ground motion simulation methods are considered as the Hybrid Integral Composite (HIC) approach introduced by Gallovic and Brokesova [6] and the Stochastic Finite-Fault (SFF) approach of Motazedian and Atkinson [5]. The simulated ground motions based on the HIC and SFF approaches have been respectively validated by the studies of Ameri et al. [16] and Ugurhan et al. [17] against the real time histories of the 2009 L'Aquila earthquake. The HIC approach used in Ameri et al. [16] is based on the representation theorem with a ksquared slip distribution over the fault plane for simulation of the low-frequency band. However, this approach uses a composite application of Brune's source time functions with a proper seismic moment and corner frequency for simulation of the high-frequency band. Then, the ground motion amplitudes are combined in a cross-over frequency band. More details on simulations can be found in Ameri et al. [16]. On the other hand, the SFF method used in Ugurhan et al. [17] is based on a dynamic corner frequency approach to simulate the whole frequency band. In this approach, the fault plane is divided into smaller subfaults where their contribution is summed in the time domain to obtain the simulated time history. It is noted that the SFF approach provides only one horizontal component of simulated motion at each station. Details of simulations can be found in Ugurhan et al. [17]. The 
Simulated PGAs corresponding to the horizontal time histories from the two methods are presented in Table 1.

Table 1. Information on the stations of the 2009 L'Aquila earthquake along with the real and simulated PGAs.

\begin{tabular}{|c|c|c|c|c|c|c|c|c|c|}
\hline $\begin{array}{c}\text { Station } \\
\text { Code }\end{array}$ & $\begin{array}{c}\text { Lat. } \\
\left(^{\circ}\right)\end{array}$ & $\begin{array}{c}\text { Long. } \\
\left(^{\circ}\right)\end{array}$ & $\begin{array}{c}\text { Site } \\
\text { Class } \\
\text { (EC8 } \\
[1])\end{array}$ & $\begin{array}{l}\mathbf{R}_{\text {EPI }} \\
(\mathbf{k m})\end{array}$ & $\begin{array}{c}\text { Obs. } \\
\text { PGA- } \\
\text { NS } \\
\left(\mathbf{c m} / \mathbf{s}^{2}\right)\end{array}$ & $\begin{array}{c}\text { Obs. } \\
\text { PGA- } \\
\text { EW } \\
\left(\mathbf{c m} / \mathbf{s}^{2}\right)\end{array}$ & $\begin{array}{c}\text { Sim. } \\
\text { PGA- } \\
\text { NS } \\
\text { HIC } \\
\left(\mathrm{cm} / \mathbf{s}^{2}\right) \\
\end{array}$ & $\begin{array}{c}\text { Sim. } \\
\text { PGA- } \\
\text { EW } \\
\text { HIC } \\
\left(\mathrm{cm} / \mathbf{s}^{2}\right)\end{array}$ & $\begin{array}{l}\text { Sim. } \\
\text { PGA- } \\
\text { SFF } \\
\left(\mathbf{c m} / \mathbf{s}^{2}\right)\end{array}$ \\
\hline AQA & 42.376 & 13.339 & B & 4.6 & 347.59 & 350.46 & 196.96 & 341.18 & 254.94 \\
\hline CLN & 42.085 & 13.521 & A & 31.64 & 76.57 & 73.49 & 50.72 & 23.75 & 75.59 \\
\hline FMG & 42.268 & 13.117 & A & 19.32 & 24.53 & 20.12 & 30.38 & 28.44 & 61.10 \\
\hline GSA & 42.421 & 13.519 & B & 18.05 & 139.02 & 131.88 & 103.31 & 195.26 & 157.36 \\
\hline LSS & 42.558 & 12.969 & A & 39.02 & 7.61 & 9.21 & 6.21 & 5.41 & 24.04 \\
\hline MTR & 42.524 & 13.245 & A & 22.35 & 51.65 & 42.17 & 16.21 & 14.44 & 54.66 \\
\hline SUL & 42.090 & 13.934 & $\mathrm{C}$ & 56.53 & 24.53 & 27.04 & 8.37 & 5.41 & 32.96 \\
\hline
\end{tabular}

\section{Selected MDOF frame structures}

In this study, for structural response evaluation, a total of nine symmetric RC frame structures with varying fundamental periods are considered. Table 2 provides information regarding the number of stories, number of bays, total mass, and fundamental period of the selected frames. Among all frames, frames F1 and F6 are selected from the existing structures in Bursa (Turkey). Frame F2 is the deficient form of frame F1 by minimizing reinforcement ratio, sectional sizes, and material strengths. Frames F3, F4, and F8 are designed according to the previous Turkish seismic design code [18]. Frames F5 and F7 are selected from the existing buildings of the Duzce damage database. Finally, frame F9 is designed based on the 1982 uniform building code in California [19]. All frames are modeled using nonlinear fiber-based beam-column elements along with Kent-Scott-Park concrete and steel with strain hardening ratio of 0.005 .

Nonlinear time history analyses of the selected RC frames are conducted in OpenSees software [20]. OpenSees software uses finite elements in order to discretize and solve the equation of motion. Since all frames are symmetric, two-dimensional modeling is employed. During numerical analyses, contributions of dead and live loads to the total mass are assumed, respectively, as $100 \%$ and $25 \%$. The fundamental period range resulting from the eigenvalue analyses of all frames varies between 0.47 and 1.3 seconds. During the NLTHA, the damping ratio of $5 \%$ is considered for the first mode of the selected frames. More details regarding the sectional and material properties, story masses, modal properties, and loads on beams for the nine frames can be found in Karimzadeh et al. [13]. 
Table 2. Properties of selected frames.

\begin{tabular}{|c|c|c|c|c|}
\hline $\begin{array}{c}\text { Frame } \\
\text { ID }\end{array}$ & $\begin{array}{c}\text { Number of } \\
\text { Stories }\end{array}$ & $\begin{array}{c}\text { Number of } \\
\text { Bays }\end{array}$ & $\begin{array}{c}\text { Total Mass } \\
(\mathbf{t})\end{array}$ & $\begin{array}{c}\text { Fundamental } \\
\text { Period (s) }\end{array}$ \\
\hline F1 & 3 & 2 & 226.50 & 0.47 \\
\hline F2 & 3 & 2 & 226.50 & 0.72 \\
\hline F3 & 3 & 3 & 153.68 & 0.53 \\
\hline F4 & 4 & 3 & 212.22 & 0.69 \\
\hline F5 & 4 & 3 & 75.30 & 0.49 \\
\hline F6 & 5 & 2 & 260.20 & 0.78 \\
\hline F7 & 5 & 4 & 166.02 & 0.52 \\
\hline F8 & 7 & 3 & 365.59 & 1.05 \\
\hline F9 & 8 & 3 & 1816.10 & 1.30 \\
\hline
\end{tabular}

\section{Simulation results in terms of logarithmic misfits}

In this study, logarithmic misfits are defined for the evaluation of the observed and simulated ground motion record sets in terms of both seismological and structural measures. For this purpose, misfits are first evaluated in terms of different seismological parameters: Fourier Amplitude Spectrum (FAS), PGA, Peak Ground Velocity (PGV), PGV to PGA ratio (PGV/PGA), Arias Intensity $\left(\mathrm{I}_{\mathrm{a}}\right)$, Cumulative Absolute Velocity (CAV), and Significant Duration $\left(\mathrm{t}_{\mathrm{eff}}\right)$ defined as the time interval of $5 \%-95 \%$ of the accumulated $\mathrm{I}_{\mathrm{a}}$. Next, misfits are investigated for a single structural demand parameter as the maximum inter-story drift ratio of selected buildings. It is noted that the maximum inter-story drift ratios for the selected frames are calculated from the NLTHA for the real time histories and two alternative simulated ground motion record datasets.

Logarithmic misfits in terms of different aforementioned seismological and structural measures are evaluated as follows:

$$
\text { Misfit= log } \mid \text { Simulated } \text { Value/Real Value } \mid
$$

Based on the formulas given above, all logarithmic misfits are calculated. It is noted that, the FAS misfit is considered as the average of logarithmic misfits within the frequency interval of 0.1 to $10 \mathrm{~Hz}$. The structural demand misfit is also calculated as the average of the misfits in terms of the inter-story drift ratios at all story levels of the frame of interest. The logarithmic misfit results are presented in Figures 1 and 2 for seismological and structural parameters, respectively. It is noted that each logarithmic misfit in terms of a certain parameter is obtained in terms of the geometric mean value of the NS and EW components at every station. 


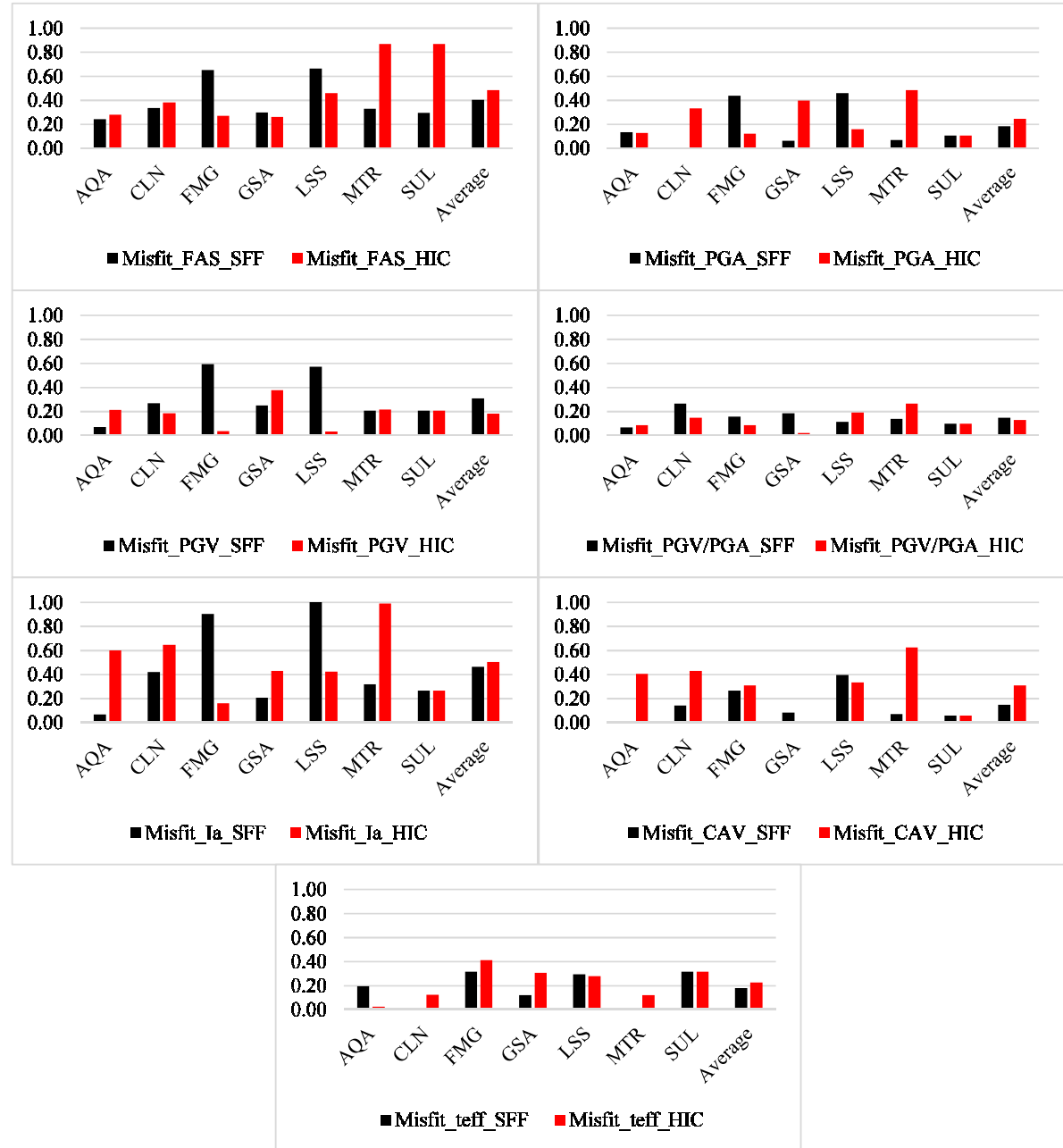

Figure 1. Seismological logarithmic misfits.

Figure 1 reveals that for all seismological parameters at the selected stations, the logarithmic misfits are smaller than 1 . However, the value of misfit varies depending on the parameter as well as the station of interest. Among all seismological parameters, the smallest misfit is obtained as 0 for PGA and $t_{\text {eff }}$ at station CLN from the SFF method and for CAV at station GSA from the HIC method. On the other hand, the largest misfit is obtained as 1 for $I_{a}$ at stations LSS from the SFF method and MTR from the HIC method. When PGA, $I_{a}, C A V$, and $t_{\text {eff }}$ are considered, it is seen that for most stations the SFF approach provides more accurate estimates than the HIC method. However, in terms of $\mathrm{PGV}$ and PGV/PGA parameters, the HIC method is more precise than the SFF approach at most stations. Overall, the average logarithmic misfits in terms of the selected seismological parameters are, respectively, calculated as 0.26 and 0.30 for the SFF and HIC approaches.

Next, results of structural logarithmic misfits are calculated for all frames and illustrated in Figure 2. Comparison of the results in Figure 2 with those obtained in Figure 1 reveals that similar to seismological logarithmic misfits, the values are less than 1 in logarithmic scale at all stations. When two alternative ground motion simulation methods are compared, it is seen that as the number of stories increases, at most stations the HIC method provides 
smaller misfits compared to the SFF approach. This can be due to the simulation of the broadband frequency range by the HIC ground motion simulation method. The minimum misfit from the SFF approach is calculated as 0.01 for the frame F8 at station SUL while from the HIC method this value is 0.02 for the frame F9 at station LSS. The maximum values of structural logarithmic misfits are calculated for frame F2 with values of 0.68 at station LSS from the SFF method and 0.66 at station MTR from the HIC method. The average logarithmic misfits in terms of the selected structural demand parameter are, respectively, calculated as 0.32 and 0.24 for the SFF and HIC approaches. This can be attributed to the inherent limitation of the SFF method in the simulation of the lowfrequency portion of the real time histories. Overall, it is seen that all seismological and structural logarithmic misfits are almost at the same level.

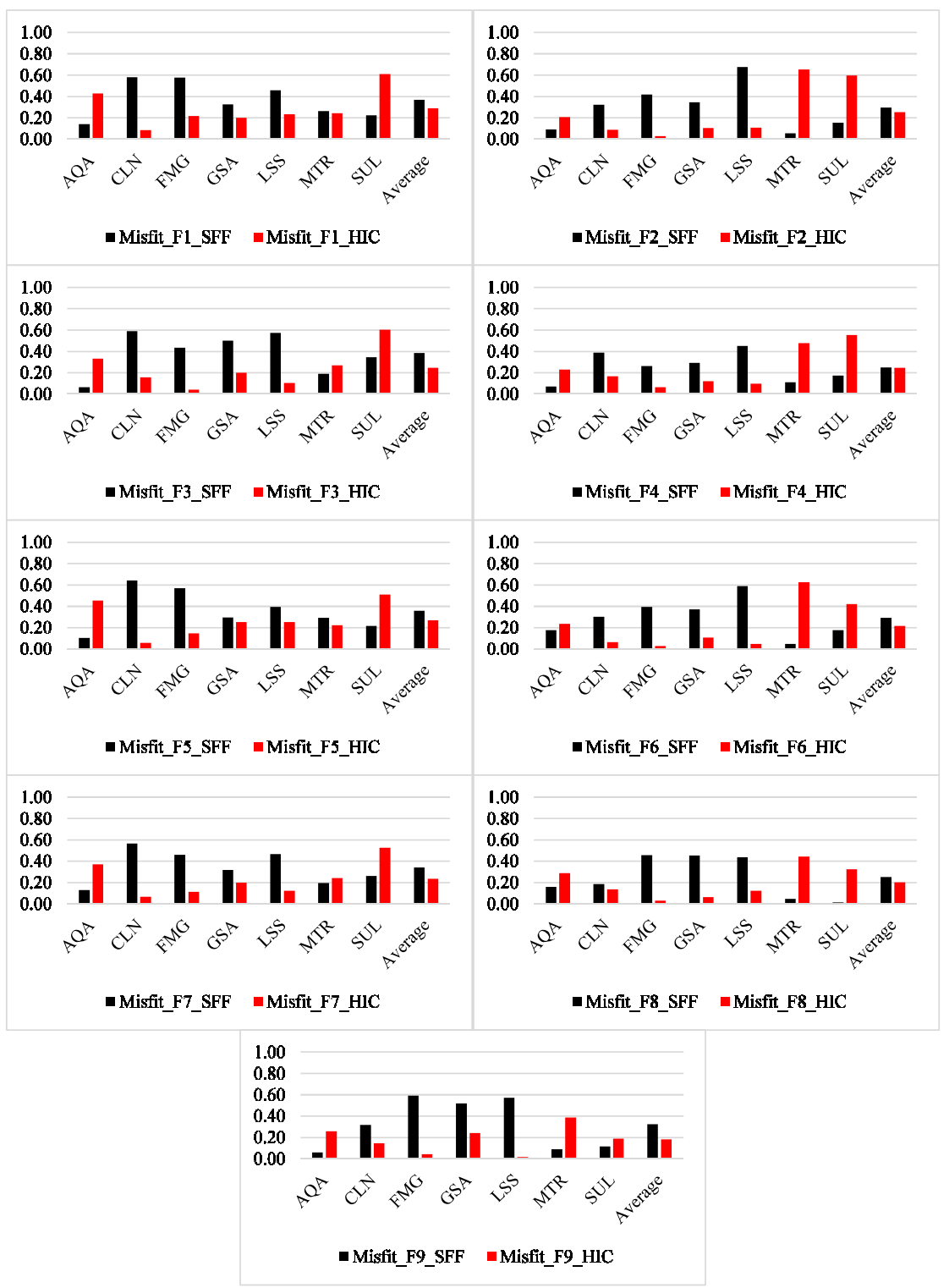

Figure 2. Structural logarithmic misfits. 


\section{Conclusions}

In this paper, the real and simulated ground motion records of the 2009 L'Aquila (Italy) earthquake $(\mathrm{Mw}=6.3)$ are evaluated for their use in engineering practice. For this purpose, the validated simulated ground motion datasets from stochastic finite-fault and hybrid integral composite ground motion simulation methods are employed. For evaluation of the simulated records, logarithmic misfits are defined and calculated for alternative seismological parameters covering the frequency, energy, and intensity contents of the time histories. Next, the logarithmic misfits are calculated for seismic demand measures. To investigate these structural misfits, different multi-degree-of-freedom reinforced concrete structures with varying number of stories and fundamental periods are considered. The investigated seismic performance measure is taken as the maximum inter-story drift ratio.

Results of this study reveal that there is variability in terms of both seismological and structural logarithmic misfits when alternative seismological parameters or different structural types are investigated. Still, the maximum level of logarithmic misfits is similar for all parameters and structures considered herein. The smallest seismological logarithmic misfit is calculated for PGA and $t_{\text {eff }}$ from SFF approach, while for CAV from HIC method. Based on both methods, the upper limit is obtained for Arias intensity. Similarly, the simulated ground motions from both methods result in close values for the minimum and maximum structural logarithmic misfits. Overall, for most stations, as the seismological logarithmic misfit increases, the structural logarithmic misfit likewise takes larger value for most frames.

Finally, in this study, misfit is investigated not only between the observed and simulated seismological measures but also between the real and estimated engineering demand parameters of various MDOF buildings. The proposed approach and similar ones can provide a means to investigate simulated time histories before their use in earthquake engineering for alternative applications.

\section{References}

1. EC8. Eurocode 8: Design of structures for earthquake resistance. Part 1: General rules, seismic actions and rules for buildings, European Norm, Management centere: Rue de Stassart 36, B-1050 Brussels, Belgium (2004).

2. ASCE/SEI 7-10. American Society of Civil Engineers. Minimum design loads for buildings and other structures (2010).

3. K.B. Olsen, R.J. Archuleta, R.J. Matarese. Three-dimensional simulation of a magnitude 7.75 earthquake on the San Andreas fault, Science, 270, 1628-1632 (1995).

4. I.A. Beresnev, G.M. Atkinson. Stochastic finite-fault modeling of ground motions from the 1994 Northridge, California, earthquake. I. Validation on rock sites, Bulletin of Seismological Society of America, 88, 6, 1392-401 (1998).

5. D. Motazedian, G.M. Atkinson, Stochastic finite-fault modeling based on a dynamic corner frequency, Bulletin of Seismological Society of America, 95, 995-1010.

6. F. Galloviç, J. Brokešová, Hybrid k-squared source model for strong ground motion simulations: Introduction, Physics and Earth Planet, 160, 34-50 (2007).

7. A. Frankel, A constant stress-drop model for producing broadband synthetic seismograms: comparison with the next generation attenuation relations, Bulletin of Seismological Society of America, 99, 2A, 664-680 (2009).

8. B.T. Aagaard, R.W. Graves, D.P. Schwartz, D.A. Ponce, R.W. Graymer, Groundmotion modeling of Hayward fault scenario earthquakes, part i: Construction of the suite of scenarios, Bulletin of Seismological Society of America, 100, 2927-2944 (2010). 
9. J.G. Anderson, Quantitative measure of the goodness-of-fit of synthetic seismograms, 13th World Conference on Earthquake Engineering, (243), 775-784, Vancouver, B.C., Canada (2004).

10. K.B. Olsen, J.E. Mayhew, Goodness-of-fit criteria for broadband synthetic seismograms, with application to the $2008 \mathrm{Mw}$ 5.4 Chino Hills, California, earthquake, Seismological Research Letters, 81, 5, 715-723 (2010).

11. A. Askan, S. Karimzadeh, M. Asten, N. Kılıç, F.N. Şişman, C. Erkmen, Assessment of seismic hazard in Erzincan (Turkey) region: construction of local velocity models and evaluation of potential ground motions, Turkish Journal of Earth Sciences, 24, 529-565 (2015).

12. M.B. Sørensen, D.H. Lang, Incorporating simulated ground motion in seismic risk assessment: Application to the lower Indian Himalayas, Earthquake Spectra, 31, 1, 7195 (2015).

13. S. Karimzadeh, A. Askan, A. Yakut, G. Ameri, Assessment of Alternative Simulation Techniques in Nonlinear Time History Analyses of Multi-Story Frame Buildings: A Case Study, Soil Dynamics and Earthquake Engineering, 98, 38-53 (2017).

14. S. Karimzadeh, A. Askan, A. Yakut, Assessment of simulated ground motions for their use in structural engineering practice; a case study for Duzce (Turkey), Pure and Applied Geophysics, 174, 9, 3325-3329 (2017).

15. S. Karimzadeh, Seismological and Engineering Demand Misfits for Evaluating Simulated Ground Motion Records, Applied Sciences, 9, 21, 4497, (2020).

16. G. Ameri, F. Gallovič, F. Pacor, Complexity of the Mw 6.3 2009 L'Aquila (central Italy) earthquake: Broadband strong-motion modeling, J. Geoph. Res. 117, B04308 (2012).

17. B. Ugurhan, A. Askan, A. Akinci, L. Malagnini, Strong ground motion simulation of the 6 April 2009 L'Aquila, Italy, Earthquake, Bulletin of Seismological Society of America, 102, 1429-1445 (2012).

18. Turkish Ministry of Public Works and Settlement, Specification for structures to be built in disaster Areas, Ankara (1997).

19. Uniform Building Code, International Conference on Building Officials (ICBO), Whittier, CA (1982).

20. OpenSees 2.4.5, Computer Software, University of California, Berkeley, CA. http://opensees.berkeley.edu. 